\title{
RESEARCH
}

Open Access

\section{Breeding strategies of open-cup-nesting birds in sub-Antarctic forests of Navarino Island, Chile}

Rocío Fernanda Jara ${ }^{1,2,3^{*}}$ (D), Ramiro Daniel Crego ${ }^{1,2,3,9}$, Francisco Javier Arellano ${ }^{2,4}$, Tomás Alberto Altamirano ${ }^{5,6}$, José Tomás Ibarra ${ }^{6,7}$, Ricardo Rozzi ${ }^{2,3,4,8}$ and Jaime Enrique Jiménez ${ }^{1,4,10}$

\begin{abstract}
Background: There is limited knowledge about the breeding strategies of birds inhabiting in South American temperate forests. This is particularly true for open-cup forest passerines breeding at high latitudes $\left(>42^{\circ}\right)$. To better understand the ecology of these species, in this study we described and compared the breeding strategies (i.e., nest dimensions, nest height from the ground, egg laying rhythm, clutch size, length of the developmental periods, breeding phenology, and diversity of nesting substrate) of five passerine birds that inhabit sub-Antarctic ecosystems.
\end{abstract}

Methods: During three breeding seasons (2014-2017), we monitored 103 nests of the five most abundant open-cup forest-dwelling passerines (Phrygilus patagonicus, Anairetes parulus, Turdus falcklandii, Elaenia albiceps, and Zonotrichia capensis) on Navarino Island $\left(55^{\circ} \mathrm{S}\right)$, Cape Horn Biosphere Reserve, southern Chile. Additionally, we compared the breeding strategies of $T$. falcklandii to another population breeding at lower latitude $\left(39^{\circ} \mathrm{S}\right)$.

Results: Most of the species started laying eggs the last week of September; only E. albiceps started 2 months later. During the breeding season of 2016-2017 both E. albiceps and Z. capensis started laying eggs earlier than the previous year. Anairetes parulus and $Z$. capensis were the most specialized in terms of nesting substrate. Turdus falcklandii had larger clutch sizes and nested closer to the ground on Navarino Island compared to the northern population, which might put this and other ground nesting species of this island at a higher risk of predation by the recently introduced American mink (Neovison vison).

Conclusions: Our five study species breed exclusively in open-cups (not in cavities) in sub-Antarctic forests, and some of them built their nests closer to the ground compared to populations breeding at lower latitudes. This may be associated with the lack of terrestrial predators on Navarino Island. Our study opens further questions about the mechanisms driving differences in breeding strategies among populations.

Keywords: Anairetes parulus, Elaenia albiceps, Latitude, Nesting, Phrygilus patagonicus, Turdus falcklandii, Zonotrichia capensis

\footnotetext{
* Correspondence: RocioJara@my.unt.edu

'Department of Biological Sciences, University of North Texas, 1511 W Sycamore, Denton, TX, USA

${ }^{2}$ Sub-Antarctic Biocultural Conservation Program, University of North Texas,

1155 Union Circle, Denton, TX, USA

Full list of author information is available at the end of the article
}

(c) The Author(s). 2019 Open Access This article is distributed under the terms of the Creative Commons Attribution 4.0 International License (http://creativecommons.org/licenses/by/4.0/), which permits unrestricted use, distribution, and reproduction in any medium, provided you give appropriate credit to the original author(s) and the source, provide a link to the Creative Commons license, and indicate if changes were made. The Creative Commons Public Domain Dedication waiver (http://creativecommons.org/publicdomain/zero/1.0/) applies to the data made available in this article, unless otherwise stated. 


\section{Background}

Despite important advances in understanding avian life history traits for many biomes, current knowledge about the breeding strategies of forest birds from southwestern South America $\left(35^{\circ}-56^{\circ} \mathrm{S}\right)$ is still very limited. Existing information for many species is based on the few studies that have been conducted in the northern section of this biome $\left(35-42^{\circ} \mathrm{S}\right)[1-5]$ and/or mostly on cavity nesters [6-9]. In this work we investigate bird reproduction of open-cup nesters at high latitudes, to provide the foundation for future hypothesis testing about breeding strategies that might affect fitness.

The southernmost forested archipelagoes of the sub-Antarctic Magellanic ecoregion are embedded in the Cape Horn Biosphere Reserve (CHBR) [10]. Navarino Island $\left(55^{\circ} \mathrm{S}\right)$ is the main island in this protected area, and its forests provide breeding and/or foraging habitat for approximately 24-28 species of birds [11, 12]. In these forests, the lack of herpetofauna and limited number of terrestrial mammals makes birds the dominant terrestrial vertebrates [13]. The most common open-cup nesting species are the Patagonian Sierra-Finch (Phrygilus patagonicus), Tufted Tit-Tyrant (Anairetes parulus), Austral Thrush (Turdus falcklandii), White-crested Elaenia (Elaenia albiceps), and Rufous-collared Sparrow (Zonotrichia capensis) [13]. Despite being locally abundant, little is known about the ecology and breeding strategies of these passerines inhabiting sub-Antarctic forests.

In Chile, these five species have extensive breeding ranges from Cape Horn $\left(56^{\circ} \mathrm{S}\right)$ to the following northernmost latitudinal limits: $P$. patagonicus to $35^{\circ} \mathrm{S}, A$. parulus to $25^{\circ} \mathrm{S}, T$. falcklandii to $27^{\circ} \mathrm{S}$, E. albiceps to $29^{\circ} \mathrm{S}$, and $Z$. capensis to $33^{\circ} \mathrm{S}$ [14]. Passerines breeding in sub-Antarctic forests are exposed to different abiotic and biotic conditions, which could result in different breeding strategies from those breeding at lower latitudes of South American temperate forests $\left(35-42^{\circ} \mathrm{S}\right)$. For example, mean temperature during the breeding season (September-February) does not exceed $8{ }^{\circ} \mathrm{C}$ in the Sub-Antarctic forests, whereas in northern sections mean temperature can reach up to $18^{\circ} \mathrm{C}$ [15]. In addition, at latitudes higher than $47^{\circ} \mathrm{S}$, the forest understory is much sparser and open, and lacks the dense growth of native and abundant bamboo species of Chusquea spp., which characterizes the understory of temperate forests north of $45^{\circ} \mathrm{S}$ [16]. The different environmental conditions may affect the breeding strategies of these species, expressed as different breeding phenologies and different resource specializations from those reported in northern habitats [17]. Furthermore, studying the breeding phenology of these species could aid the understanding of how these species could respond to global and local changes in the long-term.

In addition, until the recent introduction of the American mink (Neovison vison) [18], most forested islands south of Tierra del Fuego lacked mammalian predators [19]. Therefore, forest avifauna has evolved free of this predation pressure, leaving diurnal and nocturnal raptors as the top predators in this ecosystem. This creates an opportunity to investigate how birds have responded to the lack of ground predation pressure as compared to northern mainland populations where they evolved with a myriad of predators $[20,21]$.

Here, we studied the breeding strategies of $P$. patagonicus, A. parulus, T. falcklandii, E. albiceps, and $Z$. capensis in the sub-Antarctic forests on Navarino Island, investigating three general goals, and two questions focused on T. falklandii. (1) We characterized and compared the breeding strategies of the five species by describing their (a) nest dimensions, (b) nest height from the ground, (c) egg laying rhythm, (d) clutch size, and (e) length of the developmental periods. (2) We characterized their breeding phenology, including inter-annual variations, by recording egg-laying dates of species and conducting comparisons between two breeding seasons. Given that E. albiceps arrives at the breeding ground considerably later [13], we predicted it to start laying eggs later in the season compared to the other species. (3) We characterized the breeding habitat by quantifying breadth of nesting substrate. We expected to find differences given that anecdotal information available for these species has described some as habitat generalists, while others as more habitat specialists [4, 17]. (4) We tested if T. falcklandii places its nests closer to the ground on Navarino Island as compared to mainland populations. Given the absence of native mammal predators on Navarino Island [13], we predicted that $T$. falcklandii would place their nests closer to the ground compared to mainland populations. Finally, (5) we tested for differences in clutch size between Navarino Island and mainland populations of T. falcklandii. Following the pattern of larger clutch size towards higher latitudes [22-24], we expected larger clutch sizes for $T$. falcklandii breeding on Navarino Island than farther north.

\section{Methods}

\section{Study area}

We conducted our study on the northern coast of Navarino Island $\left(55^{\circ} \mathrm{S}\right.$; Fig. 1$)$. There, the forests are composed of a mixture of evergreen and deciduous species, and an understory of low shrubs, herbs, and diverse mosses [25]. The elevational gradient in this area is characterized by sharp slopes, with the tree line at about 600 m.a.s.l. [10]. The climate of the region is oceanic, with mild summers and winters, and with average temperatures of $10.8^{\circ} \mathrm{C}$ and $1.9^{\circ} \mathrm{C}$, respectively. The annual rainfall of $467 \mathrm{~mm}$ is equally distributed throughout the year [25]. 


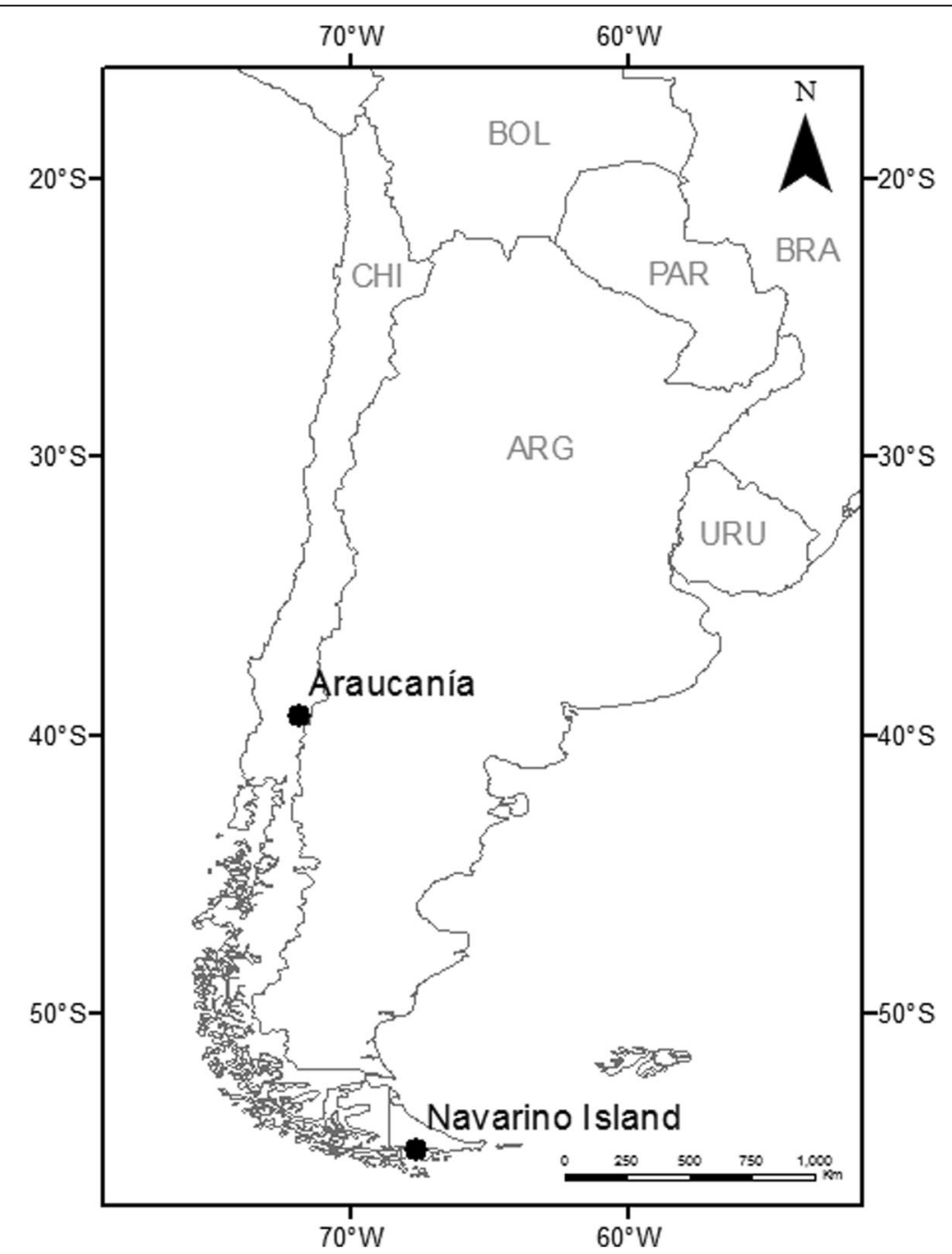

Fig. 1 Map showing the study sites. Navarino Island was the main study area, and we also present data from La Araucanía Region for Turdus falcklandii

\section{Data collection}

Our study included three breeding seasons between 2014 and 2017. During the first breeding season (2014-2015), we made exploratory observations from the end of November until early January. During the second (2015-2016) and third (2016-2017) seasons we included the whole breeding period, conducting observations from early October through mid- February and January, respectively. We located active nests (i.e., having at least one egg or nestling) in the forest based on the observation of breeding or nesting behavior of adults (i.e., we followed adults to their nest, wherever the nests were placed). We also used a thermal imaging device (FLIR One, 2014@ FLIR ${ }^{\circ}$ Systems, Inc.) to scan the vegetation where we thought there could be a nest based on adult behavior. After a nest was located, we deployed a camera trap (Bushnell Trophy Cam: Bushnell Corp., Overland Park, KS, USA) in front of it at varying distances depending on the habitat around the nest, but setting it at least $1 \mathrm{~m}$ away. We set cameras to take three pictures per detection with 1 minute delay. When a nest was located during the laying period, we delayed the deployment of the camera trap until the second half of the incubation period to avoid nest abandonment.

We typically checked nests every other day. During each nest visit, we first looked around to verify that no potential predators were nearby (particularly raptors perched) that could see our activity and could later prey on the nest. If a potential predator was present, we did not approach the nest at that time. After nest failure or fledging, we measured the nest (i.e., cup diameter, cup depth, nest diameter, and nest depth), height from the ground (measured to the rim of the nest), and recorded the substrate species (i.e., the plant species where the nest was located). For ground nests, we considered the substrate as the plant species that provided the most concealment within $30 \mathrm{~cm}$ of the nest [26]. We determined nesting stage (i.e., laying, incubating, or 
nestling) and the duration of these stages based on the data from visits and pictures from the camera trap. For example, when a change in stage occurred between visits, we used pictures from the camera trap to determine when this change happened, based on adult behavior (i.e., a change from adult sitting on nest to adult bringing food to the nest indicated that eggs have hatched). For cases in which nests were located after the day the first egg was laid, we estimated this date by subtracting the average incubation and nestling period length (both determined for our region), and clutch size (assuming one egg was laid per day) [26]. We estimated egg-laying rhythm as (\# days between 1st and last egg laid)/(\# of eggs laid), and report the minimum \# of days required per egg. During the laying period, $90 \%$ of the visits occurred between 9:30 am and 2:30 pm, and nests were visited only once per day.

\section{Statistical analyses}

We report nest dimensions (mean \pm standard error [SE]) for all the species including nest diameter, nest depth, cup diameter, and cup depth. We also estimated a ratio (nest diameter/depth) for every species to describe the shape of the nest. In addition, we report the mean and SE for nest height from the ground, clutch size, and length of developmental periods.

We compared mean egg-laying date among species as a function of breeding season, species, and their interactions, using the non-parametric two-way ANOVA ScheirerRay-Hare $(\mathrm{H})$ test. For post hoc pairwise comparisons we used a Nemenyi test with a Chi-squared approach [27]. We compared the distribution of egg-laying dates between breeding seasons for each species using a two-sample Kolmogorov-Smirnov (D) test. We plotted the distribution of egg-laying date over time for each breeding season using the beanplot [28]. Our statistical comparison did not include the first season (2014-2015) because our data did not represent a full breeding season. We considered $p<0.05$ as significant for all statistical tests.
As an indicator of the degree of nesting-habitat specialization, for each species we quantified the breadth of nesting substrate with the standardized Levins' niche breadth index $B_{s}$ [29]. The equation is $B=\frac{1}{\sum p_{i}^{2}}$, where $B$ is Levins' measure of substrate breadth and $p_{i}$ is the proportion of nests found on substrate $i$ for a particular species. We standardized $B$ as $B_{s}=\frac{B-1}{n-1}$, where $n$ is the total number of substrates used by the species of interest [30]. This index ranges from 0 to 1 , with 1 indicating the broadest niche in terms of substrate used by a species. All analyses were performed with the R programing software (version 3.4.1) [31].

\section{Comparison to other populations of $T$. falcklandii}

We compared the breeding strategies of T. falcklandii that breeds on Navarino Island to those breeding in La Araucanía Region $\left(39^{\circ}\right.$ S), Chile (Fig. 1). The study site in La Araucanía Region is also within the temperate forests of southern South America. Unlike Navarino Island, this region is inhabited by several ground predators of bird nests including carnivores and reptiles [2, 20, 21, 32, 33]. As part of a different study in La Araucanía Region, nests of $T$. falcklandii were located by adult behavior (i.e., individuals exhibiting breeding behavior were followed). Data on these particular nests have not been published, but for more details on the methodology see [34]. Using a Wilcoxon test (W) with continuity correction we compared the nest height from the ground and clutch size between $T$. falcklandii from Navarino Island and La Araucanía populations.

\section{Results}

On Navarino Island, we found 103 nests during the three seasons (P. patagonicus $n=17$, A. parulus $n=16, T$. falcklandii $n=8$, E. albiceps $n=28$, and $Z$. capensis $n=34$ ). Most nests were found during the last two seasons (2015$2016=51,2016-2017=42$ ). Additional information on sample size per species by breeding season can be found in Additional file 1. All nests were open cups (Table 1).

Table 1 Nest height from ground, and nest and cavity dimensions (cm) of five forest-nesting bird species

\begin{tabular}{|c|c|c|c|c|c|c|}
\hline Nest dimensions ${ }^{a}$ & Height from ground & Nest diameter & Nest depth & Nest diam/depth ratio & Cup diameter & Cup depth \\
\hline P. patagonicus $(n=17)$ & $74.5 \pm 10.5(0-140 ; 90)$ & $12.7 \pm 0.6$ & $7.8 \pm 0.6$ & 1.6 & $7.5 \pm 0.4$ & $6.0 \pm 1.6$ \\
\hline T. falcklandii $(n=8)$ & $36.5 \pm 19.9(0-133 ; 10)$ & $16.6 \pm 1.2$ & $8.4 \pm 2.5$ & 2.0 & $9.0 \pm 1.2$ & $5.0 \pm 0.7$ \\
\hline A. parulus $(n=16)$ & $130.1 \pm 45.5(43-800 ; 78)$ & $8.4 \pm 0.3$ & $6.9 \pm 0.4$ & 1.2 & $4.1 \pm 0.3$ & $3.7 \pm 0.4$ \\
\hline E. albiceps $(n=28)$ & $121.0 \pm 14.1(40-355 ; 99)$ & $10.2 \pm 0.4$ & $6.9 \pm 0.5$ & 1.5 & $5.4 \pm 0.2$ & $3.4 \pm 0.2$ \\
\hline Z. capensis $(n=34)$ & $3.7 \pm 2.2(0-55 ; 0)$ & $14.0 \pm 1.0$ & $5.9 \pm 0.6$ & 2.4 & $6.6 \pm 0.4$ & $4.0 \pm 0.3$ \\
\hline Cavity dimensions $^{b}$ & Height from ground & Entrance diameter & Entrance height & Interior depth & Interior height & $\mathrm{DCH}^{\mathrm{c}}$ \\
\hline T. falcklandii $(n=12)$ & $388.6 \pm 78.3(81-1120 ; 319)$ & $13.2 \pm 2.3$ & $3.9 \pm 34$ & $34.2 \pm 2.4$ & $22.0 \pm 4.4$ & $56.1 \pm 4.1$ \\
\hline
\end{tabular}

Data are expressed as means \pm 1 standard error (SE). In addition, for height from the ground, we report range and median in parenthesis

${ }^{\text {a }}$ Measurements of nests found on Navarino Island

${ }^{b}$ Measurements of the cavities used for nesting by T. falcklandii in La Araucanía Region

${ }^{c} D C H$ Diameter of the trunk at the cavity height 
Table 2 Clutch size and duration of incubation and nestling periods

\begin{tabular}{llll}
\hline & Clutch size & Incubation (days) & Nestling (days) \\
\hline P. patagonicus & $3.5 \pm 0.3(11)$ & $13.4 \pm 1.0(5)$ & $15.5 \pm 0.9(5)$ \\
A. parulus & $3.0 \pm 0.2(7)$ & $15.5 \pm 2.5(2)$ & $16.1 \pm 0.4(4)$ \\
T. falcklandii & $3.2 \pm 0.2(5)$ & - & $16.5 \pm 0.5(2)$ \\
E. albiceps & $2.2 \pm 0.1(18)$ & $14.5 \pm 0.9(3)$ & $16.1 \pm 0.4(6)$ \\
Z. capensis & $3.0 \pm 0.1(23)$ & $11.3 \pm 0.3(2)$ & $12.3 \pm 0.2(6)$ \\
\hline
\end{tabular}

Data are expressed as means \pm 1 SE with sample size in parenthesis. ${ }^{a}$ We were not able to determine the exact incubation period because all the nests found were either in the incubation or nestling period

Regarding dimensions and the shape of the nests, two species built flat nests in which the diameter/depth ratio was 2 ( $T$. falcklandii) or $>2$ (Z. capensis). In contrast, the other three species built rounded nests in which the diameter/ depth ratio were 1.2 for $A$. parulus, 1.6 for $P$. patagonicus and 1.5 for E. albiceps (Table 1). Additional information on nest building behavior is found in Additional file 2 .

One species, $Z$. capensis, built its nest most often on the ground, or very close $(<5 \mathrm{~cm})$ to it (Table 1$)$. Two other species, $T$. falcklandii and P. patagonicus, built their nests occasionally on the ground, and on average at heights less than 1 meter above the ground. Only the two smallest species did not build nests on the ground and placed them on average above a meter off the ground, reaching branches as high as up to $8 \mathrm{~m}$ (A. parulus) or $3.5 \mathrm{~m}$ ( $E$. albiceps) above the ground.
For the nests for which we were able to monitor the laying period, we estimated that the egg-laying rhythm for $P$. patagonicus was at least 1.1 days/egg $(n=2)$, for $A$. parulus was at least 2.25 days/egg $(n=1)$, for E. albiceps was at least 1.5 days/egg $(n=2)$, and for $Z$. capensis was 1 day/egg $(n=2)$. Clutch size was three eggs for three species (A. parulus, T. falcklandii, and Z. capensis), between three and four eggs for $P$. patagonicus and two eggs for E. albiceps (Table 2). Length of development periods (i.e., incubation and nestling) are shown in Table 2. When combining incubation and nestling periods, $A$. parulus had the longest developmental period (up to 32 days) and $Z$. capensis the shortest (22 days), assuming incubation starts when the last egg was laid. However, this might not necessarily be the case for every individual/ species as we recorded one case of delayed incubation in $Z$. capensis (see Additional file 2).

Most species started laying eggs in September (Fig. 2). However, egg-laying date varied significantly among species $\left(H_{4}=43.0, p<0.001\right)$. Elaenia albiceps started breeding later (last week of November) than all other species $(p<0.002)$ except $P$. patagonicus $(p=0.344)$. Interestingly, we found annual differences in egg-laying date between the last two breeding seasons $\left(H_{1}=5.3, p=0.022\right)$, but no significant interaction between seasons and species was found $\left(H_{4}=1.7, p=0.791\right)$. Specifically, $E$. albiceps $(D=0.8, p=0.035)$ and $Z$. capensis $(D=0.7, p=$ 0.001 ) started breeding earlier in the 2016-2017 season

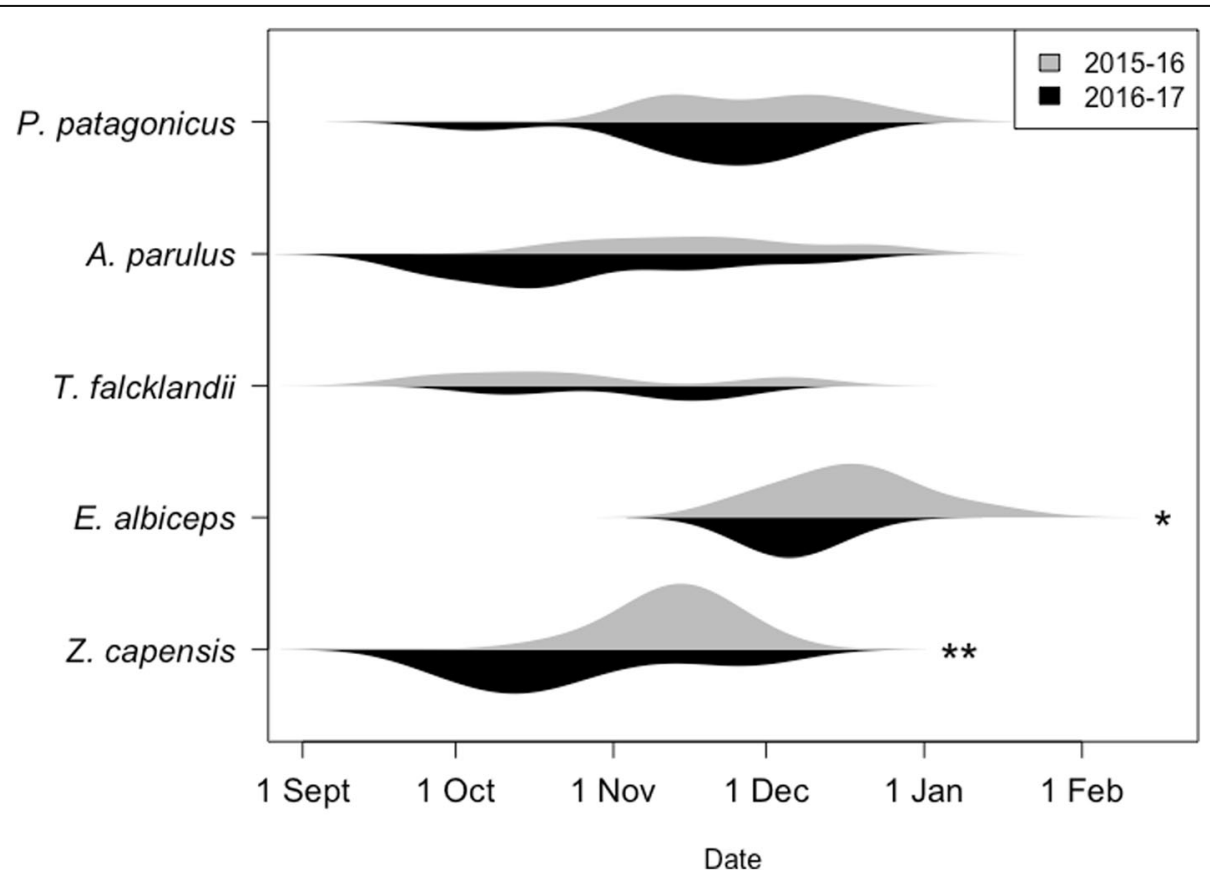

Fig. 2 Egg-laying date for five open-cup forest-nesting birds that breed on Navarino Island, southern Chile. Sample sizes per season are as follows: P. patagonicus $2015-16=7$ and $2016-17=9$, A. parulus $2015-16=5$ and $2016-17=9$, T. falcklandii $2015-16=4$ and $2016-17=3$, E. albiceps $2015-16=15$ and $2016-17=5$, and Z. capensis $2015-16=17$ and $2016-17=15 .{ }^{* *}=0.001<P<0.01,{ }^{*}=0.01<P<0.05$ for the difference between seasons assessed with a two-sample Kolmogorov-Smirnov test 
than in the previous season (Fig. 2). For the other species, we did not find statistical support for annual differences.

A total of 15 different substrates were used for nesting (Fig. 3). Of the five species studied here, A. parulus (standardized Levins' index $B_{s}=0.31$ ) and $Z$. capensis $\left(B_{s}=0.38\right)$ were the most specialized in terms of nesting substrate, with the former preferring Berberis microphylla (Magellan Barberry) and the latter forbs and grasses (Fig. 3). By contrast, the most generalist species were $T$. falcklandii $\left(B_{s}=0.87\right)$ and E. albiceps $\left(B_{s}=0.71\right)$, which used up to six and eight different substrates, respectively, without selecting a particular one (Fig. 3).

\section{Comparison to other populations of $T$. falcklandii}

In La Araucanía Region we found 12 nests of T. falcklandii. In contrast to the nests found on Navarino Island (all open-cup), all these nests were in non-excavated tree cavities (Table 1). Mean nest height from the ground was ten times higher for the population breeding in La Araucanía Region $($ mean $=389 \mathrm{~cm})$ compared to Navarino Island $(37 \mathrm{~cm}, n=8 ; W=94, p<$ 0.001 ; Fig. 4a; Table 1). Clutch size on Navarino Island (3.2 \pm 0.2 eggs, $n=5)$ was larger than that in La Araucanía Region (2.4 \pm 0.2 eggs, $n=9 ; W=8, p=0.034$; Fig. 4b).

\section{Discussion}

We report the first data on the breeding biology of the five most abundant open-cup forest-dwelling birds in their breeding grounds at the southernmost forests of the world. Although most of these species are facultative cavity nesters in other localities [34, 35], we found they exclusively built open cup nests on Navarino Island. It is noteworthy that we found differences in nesting strategies of T. falcklandii breeding at different latitudes.

In general, the relative nest abundances for each species parallels their frequency of capture in the study area during the breeding season [36]. The main exception is $P$. patagonicus, which was the most frequently captured bird [36], but represented only $17 \%$ of the nests we

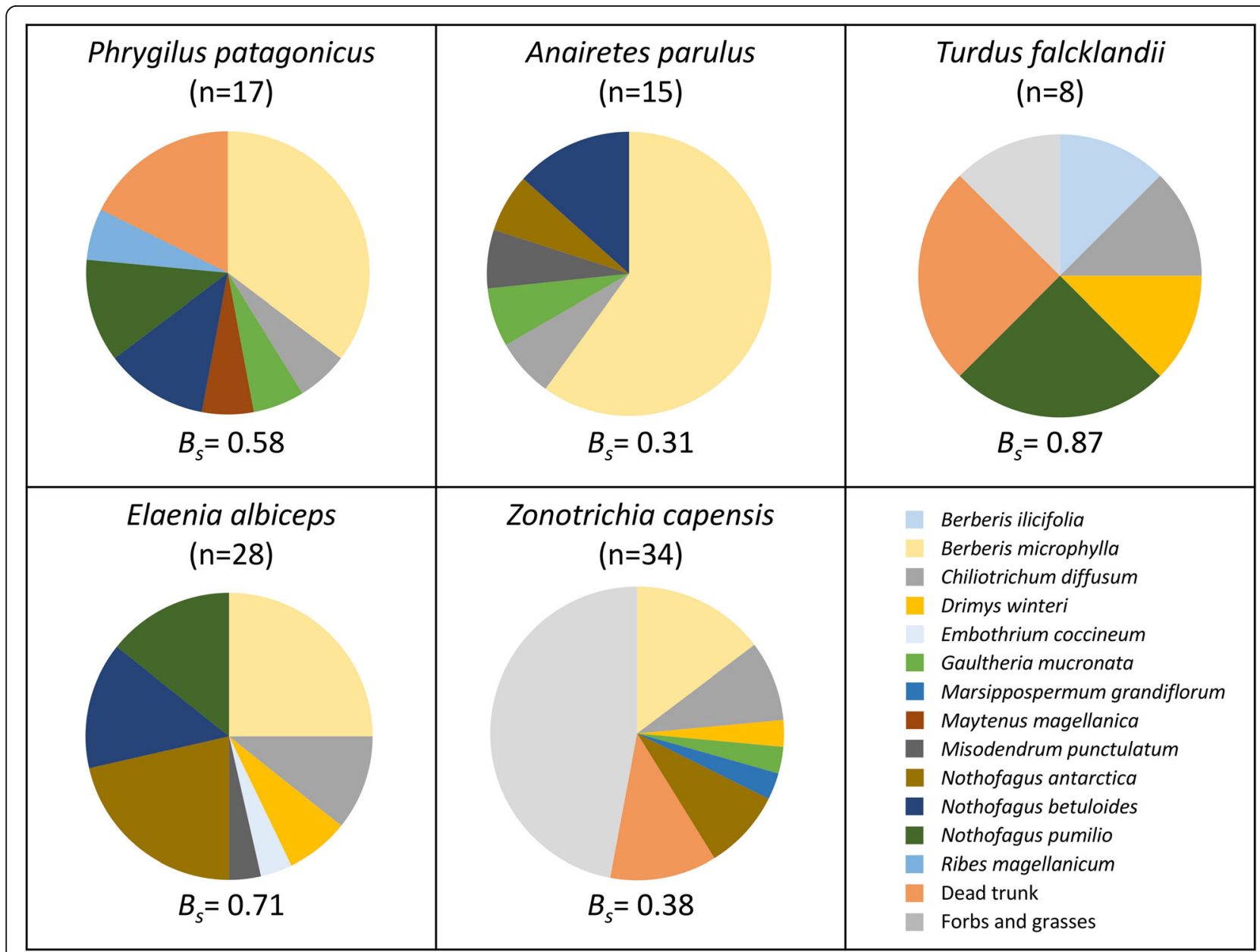

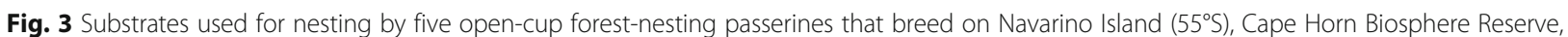
Chile. Sample sizes are in parentheses. $B_{s}$ represents the standardized Levins' niche breadth index 


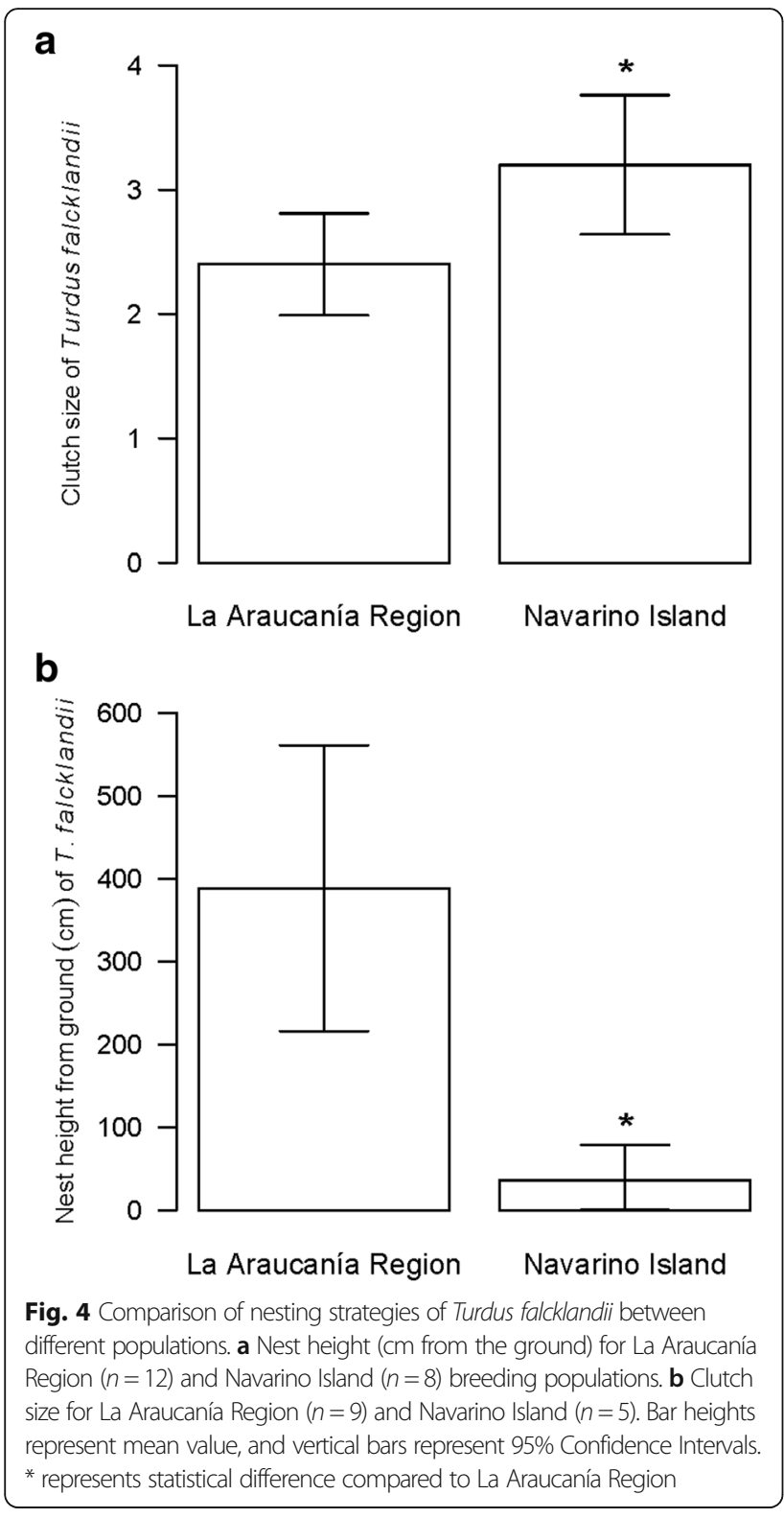

found. A possible explanation for this difference could be due to the difficulties in locating nests for this species. One cue we used to find nests was observing birds flushing from a nest. Unlike the other species, $P$. patagonicus did not flush from nests, even when we were less than $1 \mathrm{~m}$ away.

The observed nest characteristics for each species in our study generally agreed with those described in other locations [37-40]. However, farther north, four of our species have also been described nesting in cavities [34, 35]. Specifically, T. falcklandii has been described as a facultative cavity nester (10.1-90.0\% of nests in tree cavities), $P$. patagonicus as a marginal cavity nester $(1-10 \%$ of nests in cavities), and both E. albiceps and Z. capensis as incidental cavity nesters $(<1 \%$ of nests in cavities) [34,
35]. We did not find any active cavity nests for these species. This finding could be a response to the relatively low number of potential predators in the study area, as it is traditionally accepted that cavities confer protection from predators [41, 42].

The fastest egg laying rhythm was for $Z$. capensis that laid daily, and the slowest was $A$. parulus, which separated eggs by more than 2 days. Only two previous studies reported this breeding trait, both referring to $Z$. capensis, indicating the same daily laying rhythm that we report here $[43,44]$. If a nest was located after the first egg had been laid, then egg laying rhythm was taken into consideration when we estimated nest initiation date. In general, when this information is not available, authors assume one egg is laid per day (as we did in this study) $[26,43,45]$. However, as our records suggest, this does not necessarily apply to every passerine species. Given that some species, such as $A$. parulus and $E$. albiceps, might lay less than one egg per day, this assumption may bias estimation of egg laying date towards later in the season.

The present study is the first that reports developmental periods (i.e., incubation and nestling periods) for P. patagonicus, which lasted approximately 1 month from the start of incubation until chicks fledged (Table 2). Duration of these periods for $T$. falcklandii and $Z$. capensis were similar to those that have been described previously $[38,43,44,46$, 47]. The only records for A. parulus are from [38] who reports, without specifying the region, that incubation lasts 12 days and nestling 13 days. For this species, we observed longer developmental periods on Navarino Island (incubation $=15.5$ days $[n=2]$, nestling $=16.1[n=4])$. Based on only one observation in an unknown location, [38] also described the incubation and nestling period of E. albiceps as 12 and 13 days, respectively. On Navarino Island we observed somewhat longer developmental periods for this species (incubation $=14.5$ days $[n=3]$, nestling $=16.1$ days $[n=6])$. Our observations agree with the developmental periods of E. albiceps on Chiloé Island, Chile, where incubation lasts $14-15$ days and nestling 14-17 days [47].

As predicted, we found that E. albiceps breeds later compared to most of the other species. This is the only long-distance forest migratory species that breeds on Navarino Island $[48,49]$ and is the last to arrive on the breeding ground (in October). The other migratory species, $Z$. capensis, arrives in August from central Chile [36]. The same pattern occurs in central Chile, where E. albiceps breeds later than other sympatric species [5]; it arrives in September but it starts breeding in November, with its peak of breeding activity in December [4]. Interestingly, over $3500 \mathrm{~km}$ south on Navarino Island, E. albiceps also starts breeding in November, with its peak of breeding activity also in December, even though it arrives to the island in mid-October, a month 
later than the northern population. Therefore, on Navarino Island $E$. albiceps starts breeding considerably sooner (1 month) after arrival compared to lower latitude populations. This raises evolutionary questions about adaptive behaviors for a small bird worth studying along the latitudinal breeding range.

Both E. albiceps and Z. capensis started breeding earlier during the last breeding season. Coincidently, spring temperatures during the 2016-2017 breeding season were higher than the previous season. In September, the mean temperature in 2015 was $1.83^{\circ} \mathrm{C}$ $(\mathrm{SE}=0.51)$ and in 2016 it was $5.33^{\circ} \mathrm{C}(\mathrm{SE}=0.34)$ [15]. Given our limited data, we were not able to test whether there is an effect of spring temperature on egg-laying date. However, we urge scientists to implement a long-term monitoring program on the breeding phenology of these species on Navarino Island to assess whether climate change may be affecting local species. Contrastingly to these two species, we did not find annual differences in laying dates for the resident species; nevertheless, this result should be taken with caution given the limited sample size. In addition, there seems to be only one brood per species per season (Fig. 2).

As predicted, species differed in substrate used for nesting, but overall, they were generalists. The substrates used by the five species on Navarino Island coincided with reports from other locations [38, 39, 43]; however, no previous study has reported a substrate diversity index. We found that $E$. albiceps had one of the highest diversity indexes, suggesting that this species may be more adaptable to potential changes in its environment. Noteworthy, $E$. albiceps uses exotic pine plantations as a substrate for nesting in central Chile [4]. In contrast, a less substrategeneralist species such as $A$. parulus, might not be able to respond to the rapid landscape changes that are currently taking place on Navarino Island.

As predicted, and possibly associated with the lack of terrestrial predators on Navarino Island [18], we found that two of the five birds in our study area were primarily ground nesters, and the other three placed nests on average less than $1.5 \mathrm{~m}$ from the ground. Interestingly, E. albiceps and T. falcklandii on Navarino Island nested closer to the ground than populations farther north. In our study area, E. albiceps nested between $0.4 \mathrm{~m}$ and $3.6 \mathrm{~m}$ from the ground, with $50 \%$ of them under $1 \mathrm{~m}$. This only partially corresponds to what has been described for this species in a study conducted in central Chile $\left(35^{\circ} \mathrm{S}\right)$, where this species nested between 0.5 and $15 \mathrm{~m}$ above the ground [4]. Additionally, [38] described three nests for this species, all at least $2 \mathrm{~m}$ above the ground. Turdus falcklandii also nested very close to the ground (median $=10 \mathrm{~cm}$ ) on Navarino Island, which differs from what we found in La Araucanía Region
$($ median $=319 \mathrm{~cm})$ and with previous studies that have reported this species building its nests at least a few meters from the ground. In our study area, the average canopy height was about $15 \mathrm{~m}$, but we did not find nests near that height for either E. albiceps or T. falcklandii, even though these birds often feed in the canopy. Unlike the forest community in La Araucanía Region, which includes ground predators such as wild cats and foxes [20,21], on Navarino Island birds evolved in the absence of ground mammalian predators. It could be that by placing their nests closer to the ground on this island, birds avoid nest depredation by native raptors $[50,51]$. Today, this behavior could, however, put Navarino birds at a higher risk of predation by recently introduced ground predators, particularly the American mink (N. vison) $[18,52]$. Similar naivety to mink predation given the lack of coevolution was suggested for small rodents on this island [53]. However, because previous reports $[38,39]$, as well as our analysis, are based on a limited sample size, these comparisons should be taken with caution. Furthermore, placing nests closer to the ground could be a response to different biotic and abiotic factors, such as understory structure, temperature, and/or wind speed.

We found no major differences when comparing clutch sizes for the five passerines from Navarino Island to the descriptions available in the literature $[2,3,5$, 37-39, 43-46, 54-61]. However, when we made this comparison based on our data the difference in clutch size was clear. As predicted, the clutch size for T. falcklandii on Navarino Island (3-4 eggs) was statistically higher than La Araucanía Region (2-3 eggs). This corresponds with the frequently described pattern of larger clutch size at higher latitudes [22, 23, 41, 62]. It also corresponds with the pattern of larger clutch size for species nesting on islands compared to continents [63]. Finally, it could also be that a larger clutch size of $T$. falcklandii on Navarino Island is an interaction between latitude and island habitat [63].

\section{Conclusions}

This study represents the first extensive description of breeding strategies for the five most abundant forest passerine species of the sub-Antarctic forests. All of them breed exclusively in open-cups (not in cavities), and some of them built their nests closer to the ground compared to populations breeding at lower latitudes. This may be associated with the lack of terrestrial predators on Navarino Island. Our results suggest that populations of bird species with extensive breeding ranges exhibit changes along latitudinal gradients in terms of nest placement and other aspects of their breeding biology. This study opens further questions regarding the mechanisms driving differences in breeding strategies among populations. 


\section{Additional files}

Additional file 1: Number of nests by breeding season for five open-cup forest-nesting birds that breed on Navarino Island, southern Chile. We provide detailed information regarding sample size for every species by breeding season. (PDF $9 \mathrm{~kb}$ )

Additional file 2: Observations of previously unknown breeding strategies for Zonotrichia capensis, Elaenia albiceps, and Anairetes parulus. We describe observations of single events regarding unknown breeding strategies of these three species. (PDF $459 \mathrm{~kb}$ )

\section{Abbreviation}

CHBR: Cape Horn Biosphere Reserve

\section{Acknowledgments}

We kindly thank Dr. Michael D. Samuel who overviewed the data analysis and reviewed an early version of this work contributing significantly. We thank Dr. Edwin Price for providing edits to the manuscript. We also thank Carla Baros, Omar Barroso, Simon Castillo, Kristine De Leon, Josefina Kearns, Javiera Malebrán, Stephanie Pincheira, Marcela Rojas, Amanda Savage, Javiera Urrutia, Ana María Venegas, Justin Williams, and Amy Wynia for their help in the field.

\section{Funding}

Funding was provided by the Chilean National Commission for Scientific and Technological Research (CONICYT) in the form of graduate and postgraduate scholarships for RFJ and TAA respectively. Funding for fieldwork on Navarino Island was provided by the University of North Texas, Partners of the Americas fellowship, and the Institute of Ecology and Biodiversity (IEB, Basal Funding CONICYT-AFB170008). The study in the La Araucanía Region had the financial support from the Ministry of the Environment (FPA 09-0782010 y 9-I-009-12), The Peregrine Fund, The Rufford Small Grants for Nature Conservation (14397-2), Francois Vuilleumier Fund for Research on Neotropical Birds (Neotropical Ornithological Society), Idea Wild, "NETBIOAMERICAS" CONICYT/Apoyo a la Formación de Redes Internacionales entre Centros de Investigación (REDES150047), and CONICYT/FONDECYT de Inicio (11160932).

\section{Availability of data and materials}

The datasets supporting the conclusions of this article are included within the article (and its Additional files)

\section{Authors' contributions}

RFJ conducted the research, edited and analyzed the data, and wrote the draft manuscript. RFJ and RDC conceived the idea, while RR and JEJ provided considerable resources for the research, and contributed substantially to the paper. RDC, FJA, TAA, and JTI contributed with data collection and made significant contributions editing the manuscript. All authors read and approved the final manuscript.

\section{Ethics approval and consent to participate}

Not applicable.

\section{Consent for publication}

Not applicable.

\section{Competing interests}

The authors declare that they have no competing interests.

\section{Publisher's Note}

Springer Nature remains neutral with regard to jurisdictional claims in published maps and institutional affiliations.

\section{Author details}

${ }^{1}$ Department of Biological Sciences, University of North Texas, 1511 W Sycamore, Denton, TX, USA. ${ }^{2}$ Sub-Antarctic Biocultural Conservation Program, University of North Texas, 1155 Union Circle, Denton, TX, USA. ${ }^{3}$ Instituto de Ecología y Biodiversidad, Departamento de Ciencias Ecológicas, Facultad de Ciencias, Casilla 653, Santiago, Chile. ${ }^{4}$ Universidad de Magallanes, Manuel Bulnes 1855, Punta Arenas, Chile. ${ }^{5}$ Department of Forest and Conservation
Sciences, University of British Columbia, 2424 Main Mall, Vancouver, BC V6T 1Z4, Canada. ${ }^{6}$ ECOS (Ecology-Complexity-Society) Laboratory, Centre for Local Development, Education and Interculturality (CEDEL), Villarrica Campus, Pontificia Universidad Católica de Chile, O’Higgins 501, Villarrica, La Araucanía Region, Chile. ${ }^{7}$ Millennium Nucleus Center for the Socioeconomic Impact of Environmental Policies (CESIEP), Pontificia Universidad Católica de Chile, Santiago, Chile. ${ }^{8}$ Department of Philosophy and Religion, University of North Texas, 1155 Union Circle, Denton, TX, USA. ${ }^{9}$ Present Address: Smithsonian Conservation Biology Institute, Conservation Ecology Center, National Zoological Park, 1500 Remount Road, Front Royal, VA, USA. ${ }^{10}$ Advanced Environmental Research Institute, University of North Texas, Denton, TX 76203, USA

Received: 20 November 2018 Accepted: 7 May 2019

Published online: 30 May 2019

\section{References}

1. Rozzi R, Armesto J, Correa A, Torres-Mura JC, Sallabelly M. Avifauna de bosques primarios templados en islas deshabitadas del archipielago de Chiloe, Chile. Rev Chil Hist Nat. 1996:69:125-39.

2. Lazo I, Anabalón JJ. Dinámica reproductiva de un conjunto de aves passeriformes de la sabana de espinos de Chile central. Ornitol Neotrop. 1992;3:57-64.

3. Marín M. Biología reproductiva e historia natural del Zorzal (Turdus falcklandii) en Chile central. Boletín del Mus Nac Hist Nat Chile. 2015;62:12132.

4. Escobar M, Páez M, Vukasovic A, Estades C. Nidificación del migrador austral Elaenia albiceps en remanentes de bosque maulino y plantaciones de Pinus radiata en Chile central. Boletín Chil Ornitol. 2004:10:34-6.

5. Estades C. Nidificación de aves en un rodal maduro de Pinus radiata. Boletín Chil Ornitol. 1999;6:35-8.

6. Ippi S, Vásquez RA, Moreno J, Merino S, Villavicencio CP. Breeding biology of the southern house wren on Chiloé Island, southern Chile. Wilson J Ornithol. 2012;124:531-7.

7. Altamirano TA, Ibarra JT, De la Maza M, Navarrete SA, Bonacic C. Reproductive life-history variation in a secondary cavity-nester across an elevational gradient in Andean temperate ecosystems. Auk. 2015;132:826-35.

8. Quilodrán CS, Vásquez RA, Estades CF. Nesting of the Thorn-tailed Rayadito (Aphrastura spinicauda) in a pine plantation in southcentral Chile. Wilson J Ornithol. 2012:124:737-42

9. Botero-Delgadillo E, Poblete $Y$, Vásquez RA. Nestling mortality as a consequence of interspecific competition between secondary cavity nesters in the sub-Antarctic forests of Chile. Wilson J Ornithol. 2015;127:131-4.

10. Rozzi R, Massardo F, Anderson C, Heidinger K, Silander J. Ten principles for biocultural conservation at the southern tip of the Americas: the approach of the Omora Ethnobotanical Park. Ecol Soc. 2006:11:43.

11. Ippi S, Anderson CB, Rozzi R, Elphick C. Annual variation of the abundance and composition in forest bird assemblages on Navarino Island, Cape Horn biosphere reserve, Chile. Ornitol Neotrop. 2009;20:231-45.

12. Rozzi. Multi-ethnic bird guide of the sub-antarctic forests of South America. Denton: University of North Texas Press; 2010

13. Rozzi R, Jiménez JE. Magellanic Sub-Antarctic Ornithology: First Decade of Long-Term Bird Studies at the Omora Ethnobotanical Park, Cape Horn Biosphere Reserve. Chile: University of North Texas-University of Magallanes Press; 2014.

14. Medrano F, Barros R, Norambuena H, Matus R, Schmitt F. Atlas de las aves nidificantes de Chile. Santiago: Red de Observadores de Aves y Vida Silvestre de Chile; 2018.

15. Explorador Climático (CR)2. Centro de Ciencias del Clima y la Resilencia. http://explorador.cr2.cl/. Accessed 17 Jul 2017.

16. Matthei O. Las especies del género Chusquea Kunth (Poaceae: Bambusoideae), que crecen en la X Región, Chile. Gayana Botánica. 1997:54:199-220.

17. Ibarra JT, Martin K. Biotic homogenization: loss of avian functional richness and habitat specialists in disturbed Andean temperate forests. Biol Conserv. 2015;192:418-27.

18. Rozzi R, Sherriffs M. El visón (Mustela vison Schreber, carnivora: mustelidae), un nuevo mamífero exótico para la Isla Navarino. An del Inst la Patagon. 2003:31:97-104

19. Anderson CB, Rozzi R, Torres-Mura JC, McGehee SM, Sherriffs MF, Schüttler $E$, et al. Exotic vertebrate fauna in the remote and pristine sub-Antarctic Cape Horn archipelago, Chile. Biodivers Conserv. 2006;15:3295-313. 
20. Altamirano TA, Hernandez F, La MMD, Bonacic C. Güiña (Leopardus guigna) preys on cavity-nesting nestlings. Rev Chil Hist Nat. 2013;86:501-4.

21. Zúñiga A, Muñoz-Pedreros A, Fierro A. Dieta de Lycalopex griseus (Gray, 1837) (Mammalia: Canidae) en la depresión intermedia del sur de Chile. Gayana. 2008;72:113-6.

22. Cardillo M. The life-history basis of latitudinal diversity gradients: how do species traits vary from the poles to the equator? J Anim Ecol. 2002;71:79-87.

23. Jetz W, Sekercioglu CH, Bohning-Gaese K. The worldwide variation in avian clutch size across species and space. PLoS Biol. 2008:6:e303.

24. Lack D. Ecological adaptations for breeding in birds. London: Methuen \& CO Ltd; 1968.

25. Rozzi R, Jiménez JE, Massardo F, Torres-Mura JC, Rijal R. The Omora Park long-term ornithological research program: study sites and methods. In: Rozzi R, Jiménez JE, editors. Magellanic sub-Antarctic ornithology:first decade of long-term bird studies at the Omora Ethnobotanical Park, Cape Horn biosphere reserve. Chile: University of North Texas-University of Magallanes press; 2014. p. 3-39.

26. Martin TE, Paine C, Conway CJ, Hochachka WM, Allen P, Jenkins W. BBIRD field protocol; 1997

27. Pohlert T. The pairwise multiple comparison of mean ranks package (PMCMR). R package. 2014. http://cran.r-project.org/package=PMCMR.

28. Kampstra P. Beanplot: a boxplot alternative for visual comparison of distributions. J Stat Softw. 2008:28:1-9.

29. Levins R. Evolution in changing environments. Princeton: Princeton University press; 1968.

30. Colwell RK, Futuyma D. On the measurement of niche breadth and overlap. Ecology. 1971;52:567-76.

31. R Core Team. R: a language and environment for statistical computing. 2018

32. Zapata SC, Travaini A, Delibes M, Martínez-Peck R. Food habits and resource partitioning between grey and culpeo foxes in southeastern argentine Patagonia. Stud Neotrop Fauna Environ. 2005:40:97-103.

33. Menezes JC, Marini MÂ. Predators of bird nests in the Neotropics: a review. J F Ornithol. 2017:88:99-114

34. Altamirano TA, Ibarra JT, Martin K, Bonacic C. The conservation value of tree decay processes as a key driver structuring tree cavity nest webs in south American temperate rainforests. Biodivers Conserv. 2017;26:2453-72.

35. Ojeda VS, Trejo A. Primeros registros de nidificación en cavidades para tres especies de aves del bosque andino patagónico. Hornero. 2002:17:85-9.

36. Rozzi R, Jiménez JE. A summary of the birds captured with mist-nets and/or censused in the southernmost forests of the world. In: Magellanic sub-Antarctic ornithology: first decade of long-term bird studies at the Omora Ethnobotanical Park, Cape Horn biosphere reserve, Chile; 2014. p. 40-105.

37. Johnson AW. The birds of Chile and adjacent regions of Argentina, Bolivia and Peru, vol. 2. Buenos Aires: Platt Establecimientos Gráficos S.A; 1967.

38. Housse R. Las aves de Chile, en su clasificación moderna: su vida y costumbres. Santiago: Universidad de Chile; 1945.

39. Goodall JD, Johnson AW, Philippi RA. Las aves de Chile: su conocimiento y sus costumbres. Tomo primero y suplemento. Buenos Aires: Platt Establecimientos Gráficos S.A; 1957.

40. De la Peña MR. Guía de fotos de nidos: huevos y pichones de aves Argentinas. Buenos Aires: L.O.L.A - Literature of Latin America; 2006.

41. Lack D. The natural regulation of animal numbers. Oxford: Clarenden Press; 1954.

42. Nilsson SG. Evolution of hole-nesting in birds: on balancing selection pressures. Auk. 1986;103:432-5.

43. Mezquida E. La reproducción de cinco especies de Emberizidae y Fringillidae en la Reserva de Ñacuñán, Argentina. Hornero. 2003;18:13-20.

44. Mason P. The nesting biology of some passerines of Buenos Aires, Argentina. Ornithol Monogr. 1985;36:954-72.

45. Auer SK, Bassar RD, Fontaine JJ, Martin TE. Breeding biology of passerines in a subtropical montane forest in northwestern Argentina. Condor. 2007;109:321-33.

46. Fernández GJ, Duré Ruiz NM. Éxito reproductivo y productividad del chingolo (Zonotrichia capensis) en un área de monte de la Provincia de Buenos Aires (Argentina). Ornitol Neotrop. 2007:18:481-92.

47. Willson MF, Armesto JJ, Díaz J, Ojeda V, Celis-Diez JL. Chucao y otras aves del bosque templado Iluvioso de Sudamérica. 1st ed. Santiago: Corporación Instituto de Ecología y Biodiversidad; 2014.

48. Chesser RT. Seasonal distribution and ecology of south American austral migrant flycatchers. In: Greenberg R, Marra PP, editors. Birds of Two Worlds: The Ecology and Evolution of Migration. First Edit. Baltimore: JHU Press; 2005. p. $168-81$.
49. Jiménez JE, Jahn AE, Rozzi R, Seavy NE. First documented migration of individual White-crested Elaenias (Elaenia albiceps chilensis) in South America. Wilson J Ornithol. 2016;128:419-25.

50. Marzluff JM. Do pinyon jays alter nest placement based on prior experience? Anim Behav. 1988;36:1-10.

51. Peluc SI, Sillett TS, Rotenberry JT, Ghalambor CK. Adaptive phenotypic plasticity in an island songbird exposed to a novel predation risk. Behav Ecol. 2008;19:830-5.

52. Schüttler E, Klenke R, McGehee S, Rozzi R, Jax K. Vulnerability of groundnesting waterbirds to predation by invasive American mink in the Cape Horn biosphere reserve, Chile. Biol Conserv. 2009;142:1450-60.

53. Crego RD, Jiménez JE, Rozzi R. Macro- and micro-habitat selection of small rodents and their predation risk perception under a novel invasive predator at the southern end of the Americas. Mammal Res. 2018;63:267-75.

54. De la Peña MR. Guía de aves Argentinas. In: Tomo V. Passeriformes. Dendrocolaptidae - Furnariidae - Formicariidae - Tyrannidae. Buenos Aires: L. O.L.A - Literature of Latin America; 1988.

55. Hayes FE. Breeding season and clutch size of birds at Sapucái, Departamento Paraguarí, Paraguay. Boletín del Mus Nac Hist del Paraguay. 2014;18:77-97.

56. Bullock DS. Aves observadas en los alrededores de Angol. Rev Chil Hist Nat. 1929;33:171-211.

57. Barros R. Observaciones sobre el Zorzal común Turdus falklandii magellanicus King. Rev Univ. 1958;43:33-8.

58. Woods R. The Birds of the Falklands Islands. Salisbury: The Compton Press Ltd; 1975.

59. Germain MF. Notes upon the mode and place of nidification of some of the birds of Chili. Proc Bost Soc Nat Hist. 1860;7:308-16.

60. Millie WR. Las aves del valle del Huasco y sus alrededores (provincia de Atacama). Rev Chil Hist Nat. 1938;42:181-205.

61. Barron DG, Brawn JD, Weatherhead PJ. Meta-analysis of transmitter effects on avian behaviour and ecology. Methods Ecol Evol. 2010;1:180-7.

62. Rose AP, Lyon BE. Day length, reproductive effort, and the avian latitudinal clutch size gradient. Ecology. 2013;94:1327-37.

63. Covas R. Evolution of reproductive life histories in island birds worldwide. Proc R Soc B Biol Sci. 2012;279:1531-7.
Ready to submit your research? Choose BMC and benefit from:

- fast, convenient online submission

- thorough peer review by experienced researchers in your field

- rapid publication on acceptance

- support for research data, including large and complex data types

- gold Open Access which fosters wider collaboration and increased citations

- maximum visibility for your research: over 100M website views per year

At BMC, research is always in progress.

Learn more biomedcentral.com/submissions 